\title{
Origin of Chlorophyll Fluorescence in Plants at $55-75^{\circ} \mathrm{C}^{\mp}$
}

\author{
Petr llík ${ }^{\star 1,2}$, Roman Kouřil ${ }^{1}$, Jerzy Kruk ${ }^{2}$, Beata Myśliwa-Kurdziel ${ }^{2}$, Hana Popelková ${ }^{1,3}$, \\ Kazimierz Strzałka ${ }^{2}$ and Jan Nauš ${ }^{1}$ \\ ${ }^{1}$ Laboratory of Biophysics, Department of Experimental Physics, Palacký University, Olomouc, Czech Republic; \\ ${ }^{2}$ Department of Plant Physiology and Biochemistry, The Jan Zurzycki Institute of Molecular Biology and Biotechnology, \\ Jagiellonian University, Kraków, Poland and \\ ${ }^{3}$ Department of Biology, University of Michigan, Ann Arbor, MI
}

Received 2 July 2002; accepted 14 October 2002

\begin{abstract}
The origin of heat-induced chlorophyll fluorescence rise that appears at about $55-60^{\circ} \mathrm{C}$ during linear heating of leaves, chloroplasts or thylakoids (especially with a reduced content of grana thylakoids) was studied. This fluorescence rise was earlier attributed to photosystem I (PSI) emission. Our data show that the fluorescence rise originates from chlorophyll $a$ (Chl $a$ ) molecules released from chlorophyll-containing protein complexes denaturing at $55-60^{\circ} \mathrm{C}$. This conclusion results mainly from Chl $a$ fluorescence lifetime measurements with barley leaves of different $\mathrm{Chl} a$ content and absorption and emission spectra measurements with barley leaves preheated to selected temperatures. These data, supported by measurements of liposomes with different $\mathrm{Chl} a$ /lipid ratios, suggest that the released $\mathrm{Chl} a$ is dissolved in lipids of thylakoid membranes and that with increasing $\mathrm{Chl} a$ content in the lipid phase, the released $\mathrm{Chl} a$ tends to form low-fluorescing aggregates. This is probably the reason for the suppressed fluorescence rise at $55-60^{\circ} \mathrm{C}$ and the decreasing fluorescence course at $60-75^{\circ} \mathrm{C}$, which are observable during linear heating of plant material with a high $\mathrm{Chl} a$ /lipid ratio (e.g. green leaves, grana thylakoids, isolated PSII particles).
\end{abstract}

\section{INTRODUCTION}

Heat-induced changes in chlorophyll $a$ (Chl $a$ ) fluorescence intensity detected during linear heating of isolated chloroplasts, algae or whole-leaf segments (fluorescence temperature curve

TPosted on the website on 5 November 2002.

*To whom correspondence should be addressed at: Laboratory of Biophysics, Department of Experimental Physics, Palacký University, tř. Svobody 26, 77146 Olomouc, Czech Republic. Fax: 420-68-5225737; e-mail: ilik@risc.upol.cz

Abbreviations: DCMU, dichlorophenyldimethyl urea; DGDG, digalactosyldiacylglycerol; $\mathrm{F}_{\mathrm{M}}$, maximal fluorescence (photosystems II are closed); FTC, fluorescence temperature curve; Chl $a(b)$, chlorophyll $a(b)$; IML, intermittent light; LHC(II), light-harvesting complex (of photosystem II); M1, first maximum in FTC; M2, second maximum (region) in FTC; MGDG, monogalactosyldiacylglycerol; PAR, photosynthetically active radiation $(400-700 \mathrm{~nm})$; PG, phosphatidylglycerol; PPC, pigment-protein complex; PSI(II), photosystem I(II); $\mathrm{Q}_{\mathrm{A}(\mathrm{B})}$, primary (secondary) quinone acceptor of PSII; SD, standard deviation; SQDG, sulphoquinovosyldiacylglycerol.

(C) 2003 American Society for Photobiology 0031-8655/01 $\$ 5.00+0.00$
[FTC]) under weak exciting light are often used in the study of heat stress at the level of thylakoid membranes (e.g. 1-5). A steep fluorescence rise to the first maximum in FTC (M1), usually appearing within $40-50^{\circ} \mathrm{C}$ (for illustration see results in Fig. 1), corresponds with the irreversible conversion of active photosystems II (PSII), which have functional electron transport from the primary $\left(\mathrm{Q}_{\mathrm{A}}\right)$ to the secondary stable electron acceptor $\left(\mathrm{Q}_{\mathrm{B}}\right)$, to inactive PSII (6-9). Although the detailed molecular mechanism of this process is under intensive investigation (10-13), the critical temperature of this fluorescence rise is frequently used for determination of PSII thermostability $(3,14,15)$.

At the temperature of the M1 FTC maximum (around $50^{\circ} \mathrm{C}$ ) and above, the chlorophyll fluorescence intensity reflects the so-called maximal fluorescence $\left(\mathrm{F}_{\mathrm{M}}\right)$ level (when $\mathrm{Q}_{\mathrm{A}}$ is reduced) even under a weak exciting light $(2,16,17)$, as can be verified by an additional saturation light pulse, which does not enhance Chl $a$ fluorescence yield (13). Although PSII are "closed" in this sense, the charge separation and stabilization within PSII are still functional up to about $55-60^{\circ} \mathrm{C}(18-20)$.

Room temperature chlorophyll fluorescence in vivo is being attributed to the internal antennae of PSII (see Kraus and Weis [21] and Govindjee [22]). We tend to interpret the FTC shape within the whole temperature interval of $25-55^{\circ} \mathrm{C}$ by changes in fluorescence intensity from the PSII internal antennae because no significant changes in the emission spectra were observed during heating of barley leaves (5) and because a similar FTC, as that with leaves, was detected with oxygen-evolving PSII cores (lacking lightharvesting complexes of PSII [LHCII]) in this temperature range (23). This seems to be in contradiction to several studies on thylakoid membranes indicating that LHCII separate from PSII cores above $40^{\circ} \mathrm{C}(24-26)$; however, there is no evidence that the detached LHCII contribute to fluorescence emission in vivo in this temperature range.

The FTC phase between $50^{\circ} \mathrm{C}$ and $55^{\circ} \mathrm{C}$ is decreasing, which seems to be part of a more general monotonous $\mathrm{F}_{\mathrm{M}}$ decrease, which was detected in the temperature range from $-100^{\circ} \mathrm{C}$ to $+60^{\circ} \mathrm{C}$ with dichlorophenyldimethyl urea (DCMU)-treated leaves (17). This temperature dependence of the $\mathrm{F}_{\mathrm{M}}$ level was interpreted by an increasing rate of internal conversion of $\mathrm{Chl} a$ molecules themselves because it was also successfully simulated by a mathematical model (16).

A steep fluorescence rise to the second maximum (region) in FTC (M2) can be observed in FTC at about $55-60^{\circ} \mathrm{C}$, mainly for samples with reduced LHCII content (27-33). This fluorescence 


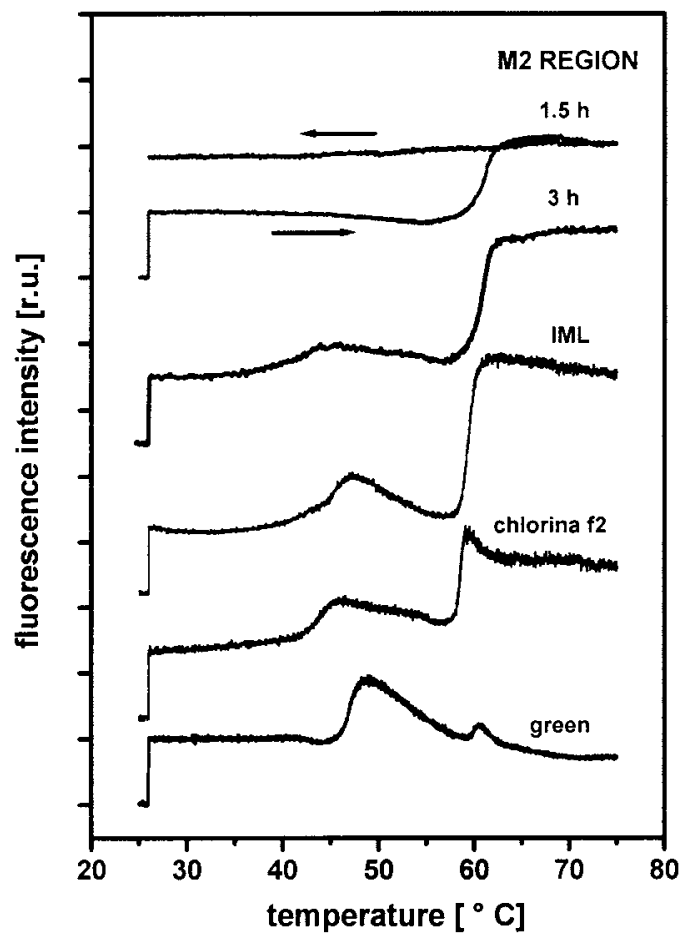

Figure 1. FTC of barley leaves at different stages of development. From the top: barley leaf greening for 1.5 and $3 \mathrm{~h}$ in continuous light, IML-grown leaf, Chl $b$-less chlorina $f 2$ leaf, and green leaf. All FTC are normalized for the fluorescence intensity at $25^{\circ} \mathrm{C}$. Excitation and emission wavelength were 436 and $675 \mathrm{~nm}$, respectively. Linear heating rate was $2^{\circ} \mathrm{C} \min ^{-1}$. M2 region-a part of FTC from the second fluorescence rise to $75^{\circ} \mathrm{C}$.

rise is irreversible $(27,34)$, and the temperature of this rise increases greatly with an increase in heating rate (35). The fluorescence rise corresponds with drastic morphological changes within plant cells. Thylakoids burst and create condensed structures (36), chloroplast membrane and plasmalema loses its semipermeability $(37,38)$, and an ion leakage from plant cells can be detected (e.g. 38). Downton and Berry (28) attributed this high-temperature fluorescence rise to PSI emission and proposed the use of the relative height of this rise for estimation of nonappressed to appressed thylakoids in chloroplasts. However, it was shown that this fluorescence rise also appeared in the FTC measured with the green alga mutant Chlamydomonas reinhardtii lacking PSI (29); thus, the attribution by Downton and Berry was questioned. Recently, it has been shown that the fluorescence rise also appears in leaves of $\mathrm{Chl} b-$ less chlorina $f 2$ barley and that chlorophylls do not degrade during FTC measurement up to $75^{\circ} \mathrm{C}$ (5), indicating that $\mathrm{Chl} a$ molecules are really responsible for the fluorescence rise. Analysis of the emission spectra detected during this fluorescence rise in barley leaves showed that this high-temperature fluorescence comes from a short-wavelength $\mathrm{Chl}$ a spectral form with the emission maximum at about $675 \mathrm{~nm}$. A concomitant blueshift of the main absorption maximum in the red region concluded that the fluorescence rise reflects weakening of the $\mathrm{Chl} a$-protein interaction in the thylakoid membrane (5).

In FTC above $60^{\circ} \mathrm{C}$, fluorescence usually decreases, mainly for samples with a higher LHC content $(28,31,35)$. When samples with a lower LHC content are used, the fluorescence level is rather constant within $60-75^{\circ} \mathrm{C}(5,31,32)$. The reason for this dependence has not been explained yet.
Although FTC above $55^{\circ} \mathrm{C}$ reflects nonphysiological changes in thylakoid membranes, a study of chlorophyll fluorescence changes at these temperatures could be relevant for chlorophyll thermoluminescence and chemiluminescence studies because a similar heating regime is used in these methods. In this work we present evidence that the steep high-temperature chlorophyll fluorescence rise appearing in FTC at around $55-60^{\circ} \mathrm{C}$ originates from $\mathrm{Chl}$ $a$ molecules released from pigment-protein complexes (PPC), in all probability to the lipid phase. A suppression of this fluorescence rise and the subsequent fluorescence decrease observed above $60^{\circ} \mathrm{C}$ in samples with a high $\mathrm{Chl} a$ content is explained by an aggregation of the released $\mathrm{Chl} a$ in the surrounding lipid phase.

\section{MATERIALS AND METHODS}

Plant material. Hordeum vulgare L. (cv. Akcent) and the Chl $b$-less barley mutant chlorina $f 2$ were cultivated in artificial soil composed of perlit and Knop solution under a light regime of $16 \mathrm{~h}$ white light $(90 \mu \mathrm{mol}$ photons $\mathrm{m}^{-2} \mathrm{~s}^{-1}$ of photosynthetically active radiation [PAR]) and $8 \mathrm{~h}$ darkness. Greening barley seedlings were prepared from etiolated barley leaves precultivated for 5.5 days in the dark. These etiolated seedlings were irradiated for 1.5 or $3 \mathrm{~h}$ in white light $\left(90 \mu \mathrm{mol}\right.$ photons $\mathrm{m}^{-2} \mathrm{~s}^{-1}$ of PAR). All the above cultivations were performed at $24 \pm 1{ }^{\circ} \mathrm{C}$. Intermittent light (IML)-grown barley seedlings were cultivated from 5 day old etiolated seedlings at $20^{\circ} \mathrm{C}$. The etiolated seedlings were exposed to IML with a regime of $2 \mathrm{~min}$ white light $\left(45 \mu \mathrm{mol}\right.$ photons $\mathrm{m}^{-2} \mathrm{~s}^{-1}$ of PAR $)$ and 98 min darkness for $41-44$ cycles (32). The middle parts of primary leaf blades were used for the measurements.

Pigment content. The content of $\mathrm{Chl} a, \mathrm{Chl} b$ and total carotenoids was determined spectrophotometrically in $80 \%$ acetone according to Lichtenthaler (39). Means \pm standard deviation (SD) were calculated from three to four independent measurements.

Fluorescence temperature curves. The curves were measured using a fluorescence spectrophotometer F-4500 (Hitachi, Tokyo, Japan) extended by a laboratory setup with fiber optics, allowing measurements outside the sample chamber. Fluorescence was excited on the adaxial leaf side at $436 \mathrm{~nm}\left(10 \mu \mathrm{mol}\right.$ photons $\left.\mathrm{m}^{-2} \mathrm{~s}^{-1}\right)$ and detected at $675 \mathrm{~nm}$. The spectral slit-widths for excitation and emission monochromator were 10 and $5 \mathrm{~nm}$, respectively. The leaf segments were placed on the sample holder, immersed in distilled water and linearly heated at a rate of $2^{\circ} \mathrm{C} \mathrm{min}{ }^{-1}$ from room temperature up to the selected temperature. Linearity of heating was ensured by a computer-controlled electric heater. A magnetic stirrer stirred the water in the vessel.

Fluorescence lifetime measurements. The fluorescence lifetime measurements were performed using the K2 multifrequency cross-correlation phase and modulation fluorometer (ISS Inc., Urbana, IL) at room temperature in the frequency range of $2-250 \mathrm{MHz}$ as described previously by MyśliwaKurdziel et al. $(40,41)$. Adaxial leaf side or liposomes with Chl $a$ (see below) were excited by weak $440 \mathrm{~nm}$ light (integral light intensity < $0.1 \mu \mathrm{mol}$ photons $\mathrm{m}^{-2} \mathrm{~s}^{-1}$ ). Fluorescence was detected above $630 \mathrm{~nm}$. For each frequency, phase and modulation were measured with reference to a scattering solution of glycogen in water. Phase and modulation data were fitted by a 1-3 exponential decay model using ISSL decay acquisition software supplied with the fluorometer. The quality of the fits was judged by $\chi^{2}$ values and by plots of weighted residuals. Because the variances of output fitted parameters (lifetimes and fractions) for a given data set (4-7 repetitions) mostly exceeded the variances of output parameters given by the fitting procedure, the means and standard deviations calculated from the fitted parameters of each given data set were presented. The fraction indicates the relative fluorescence intensity observed in the usual steadystate fluorescence measurement due to each decay component.

Absorption and fluorescence emission spectra of leaves. Absorption spectra of leaf segments were measured during linear heating at a rate of $2^{\circ} \mathrm{C} \mathrm{min}^{-1}$ with a Helios $\alpha$ spectrophotometer (Unicam, Cambridge, UK). Samples were placed into a glass cuvette with distilled water. Spectra were measured at selected temperatures with a $2 \mathrm{~nm}$ spectral slitwidth. Fluorescence emission spectra of leaf segments at different temperatures $\left(-196^{\circ} \mathrm{C},+61^{\circ} \mathrm{C}\right)$ were measured with a fluorescence spectrophotometer F-4500 (Hitachi). The parameters of the measurement were the same as for the FTC measurement. The preheated leaf segment was immersed in liquid nitrogen in a custom-made Dewar flask. Spectra were 
recorded during spontaneous heating of the sample from $77 \mathrm{~K}$ to room temperature. The actual temperature was measured using a thermocouple (Cu-constantan) placed on the adaxial side of the leaf segment.

Preparation and spectral measurements of liposomes containing Chl a. Appropriate volumes of stock solutions of monogalactosyldiacylglycerol (MGDG), digalactosyldiacylglycerol (DGDG), sulphoquinovosyldiacylglycerol (SQDG) and phosphatidylglycerol (PG) in chloroform-methanol (Lipid Products Ltd., Surrey, UK) and pure Chl $a$ (Sigma-Aldrich Co., St. Louis, MO) in acetone were transferred to an Eppendorf tube and mixed and evaporated to dryness in a stream of nitrogen. The samples were then dried for $30 \mathrm{~min}$ under low pressure. Subsequently, $25 \mu \mathrm{L}$ of absolute ethanol was added, the samples shaken to dissolve the Chl $a$-lipid mixture and $20 \mu \mathrm{L}$ of this solution slowly injected with a Hamilton syringe into 1 $\mathrm{mL}$ of buffer (25 $\mathrm{m} M N$-2-hydroxyethylpiperazine- $N^{\prime}$-2-ethane-sulfonic acid, $\mathrm{pH}$ 7.5) for lipid/Chl $a$ molar proportions of 1000, 500, 250 and 125; into $2 \mathrm{~mL}$ of the buffer for a ratio of 62 ; into $4 \mathrm{~mL}$ for a ratio of 31 ; into 8 $\mathrm{mL}$ for a ratio of 16 and into $16 \mathrm{~mL}$ for a ratio of 8 . The final lipid concentrations in the $1000,500,250$ and 125 samples was $0.5 \mathrm{mg} \mathrm{ml}^{-1}$ $(0.611 \mathrm{mM})$. For all samples the lipid composition was MGDG:DGDG:SQDG:PG $=50: 25: 12.5: 12.5(\mathrm{~mol} / \mathrm{mol})$. The samples were measured in $0.5 \times 0.5 \mathrm{~cm}$ cuvettes. Fluorescence emission spectra of the liposomes were measured with a luminescence spectrofluorimeter LS50B (Perkin Elmer, Norwalk, CT) under excitation at $440 \mathrm{~nm}$. The spectral slit-widths of the excitation and emission monochromators were 5 and 2.5 $\mathrm{nm}$, respectively.

\section{RESULTS}

\section{M2 FTC region in leaves at different stages of development}

Figure 1 shows FTC of barley leaves of different types. The etiolated leaf after $1.5 \mathrm{~h}$ greening in continuous light has a very low chlorophyll content (Table 1), and the chlorophyll is incorporated mainly to PSI and PSII core complexes (42). The FTC of this leaf (upper curve) lacks the florescence rise to the first maximum, which appears at $45-50^{\circ} \mathrm{C}$ and reflects PSII "closure" (see the Introduction). This was expected because the electron transport through the forming PSII core in such a leaf is still not active (42). However, a marked fluorescence rise to the M2 FTC region appears around $60^{\circ} \mathrm{C}$, followed by a relatively constant fluorescence transient up to $75^{\circ} \mathrm{C}$. The irreversibility of this fluorescence rise is also documented (Fig. 1).

Another FTC in Fig. 1 is that of barley leaf greened for $3 \mathrm{~h}$ in continuous light, when LHCII complexes begin to appear $(31,42,43)$. For this sample the first FTC maximum at about $46^{\circ} \mathrm{C}$ and a pronounced fluorescence rise to the M2 FTC region was observed. The third FTC in Fig. 1 (middle curve) is that of the IML-grown barley leaf with a greatly reduced content of LHC (see, e.g. Król et al. [44]). Here, a rise to the first FTC maximum, reflecting a regular PSII function (8), and a more pronounced fluorescence rise to the M2 FTC region can be seen. In this case a slight fluorescence decrease also appears in the M2 FTC region. The fourth FTC was measured with the Chl $b$-less barley mutant chlorina 2 , which lacks or has a reduced content of several LHC (44), but its Chl $a$ content is higher than that of all the leaf types mentioned above (Table 1). In this FTC the first FTC maximum appears at a relatively low temperature $\left(46^{\circ} \mathrm{C}\right)$, as in the FTC of the leaf after $3 \mathrm{~h}$ greening, which can be explained by their relatively low PSII thermostability (45). The fluorescence rise to the M2 FTC region is again clearly visible and is followed by a significant fluorescence decrease above $60^{\circ} \mathrm{C}$. The FTC of green barley leaf (Fig. 1, curve below) has the M2 FTC region markedly suppressed, and the fluorescence rise to the $\mathrm{M} 2$ region almost disappears.

It was shown several times that the height of the M2 FTC region is greatly reduced for leaves of the same species with lower Chl a/
Table 1. Chl $a, \mathrm{Chl} b$ and sum of carotenoid concentrations per leaf area $\left(\mu \mathrm{g} \mathrm{cm}^{-2}\right)$; Chl $a / \mathrm{Chl} b$ ratio and height of the M2 FTC maximum (region) relative to the fluorescence intensity at $25^{\circ} \mathrm{C}(\mathrm{M} 2 / \mathrm{F}(\mathrm{T} 25)$ ) for five barley leaf types at different stages of development (see the caption of Fig. 1)

\begin{tabular}{lccccc}
\hline & Chl $a$ & Chl $b$ & Car & $\begin{array}{c}\text { Chl } a / \\
\text { Chl } b\end{array}$ & $\begin{array}{c}\text { M2/F } \\
(\mathrm{T} 25)\end{array}$ \\
\hline $\begin{array}{l}1.5 \mathrm{~h} \\
\text { greening }\end{array}$ & $0.4 \pm 0.1$ & $<0.02$ & $1.0 \pm 0.6$ & $>20$ & 2.0 \\
$\begin{array}{l}3 \text { h } \\
\text { greening }\end{array}$ & $1.8 \pm 0.3$ & $0.20 \pm 0.05$ & $1.2 \pm 0.3$ & $9.0 \pm 3.7$ & 3.2 \\
$\begin{array}{l}\text { IML } \\
\text { chlorina } f 2\end{array}$ & $10.8 \pm 0.3$ & $0.30 \pm 0.06$ & $1.1 \pm 0.2$ & $7.3 \pm 2.4$ & 3.5 \\
Green & $22.2 \pm 0.8$ & $7.3 \pm 0.2$ & $2.5 \pm 0.3$ & $\infty$ & 2.8 \\
\hline
\end{tabular}

Chl $b$ ratios $(28,30,31,46)$. We evaluated the relative heights of the $\mathrm{M} 2 \mathrm{FTC}$ regions (calculated as the $\mathrm{F}_{\mathrm{M}}$ intensity in the M2 region divided by the fluorescence intensity at $25^{\circ} \mathrm{C}$ ) for these barley leaves at different stages of development and compared them with their Chl $a / \mathrm{Chl} b$ ratios (Table 1). We can therefore state that even within one species there is no clear correspondence between these two parameters. It rather seems that the height of the M2 FTC region is proportional to the $\mathrm{Chl} a$ concentration in the leaf and that this proportionality turns to inverse dependence for higher $\mathrm{Chl}$ $a$ concentrations (see also Fig. 1). In our case the turn in this dependence appears in the IML leaf. In the M2 FTC region of this leaf, a fluorescence decrease also begins to appear (Fig. 1). A pronounced decrease in the M2 FTC region is visible for chlorina $f 2$ and green leaves having higher Chl $a$ concentrations (Table 1).

\section{Chlorophyll fluorescence lifetimes of preheated leaves}

We measured the chlorophyll fluorescence lifetimes of barley leaves preheated to selected temperatures corresponding to important points in the FTC. Initially, two leaf types, $3 \mathrm{~h}$ greening and green barley leaves, were chosen for the measurements, the first as a sample with a pronounced M2 FTC region (without fluorescence decrease in this region) and the second as a sample with a greatly reduced M2 region (see Fig. 1). The fluorescence lifetime measurements were performed at room temperature (after cooling down of the leaves from selected higher temperatures); thus, irreversible fluorescence changes were detected. However, the steep fluorescence rises in FTC appearing at $40-50^{\circ} \mathrm{C}$ and $55-$ $60^{\circ} \mathrm{C}$ are both irreversible (see the Introduction and also Fig. 1).

For the leaves greening for $3 \mathrm{~h}$, preheated up to $60^{\circ} \mathrm{C}$, the frequency dependencies of fluorescence modulation and phase shift were fitted successfully by a two-exponential decay model (Fig. 2). The fluorescence lifetimes of both decay components$\tau_{\text {fast }}<0.1 \mathrm{~ns}$ and $\tau_{\text {middle }} \sim 2 \mathrm{~ns}$ - did not change with preheating temperatures up to $60^{\circ} \mathrm{C}$ in contrast to their fractions (relative contributions of decay components to the steady-state fluorescence level). Whereas in unheated $3 \mathrm{~h}$ greening leaves, the fast component appeared with the $63 \%$ fraction, in leaves heated to $46^{\circ} \mathrm{C}$ and $55^{\circ} \mathrm{C}$, this fraction was lowered to about $40 \%$. A similar decrease in the fraction of the fast component in favor of that with higher fluorescence lifetimes was detected in thylakoid membranes and PSII cores after treatment by DCMU (47), an inhibitor of electron flow from $\mathrm{Q}_{\mathrm{A}}$ to $\mathrm{Q}_{\mathrm{B}}$. Thus, our result can be explained by a heat-induced conversion of active PSII to inactive ones (see the 
$3 \mathrm{~h}$ greening
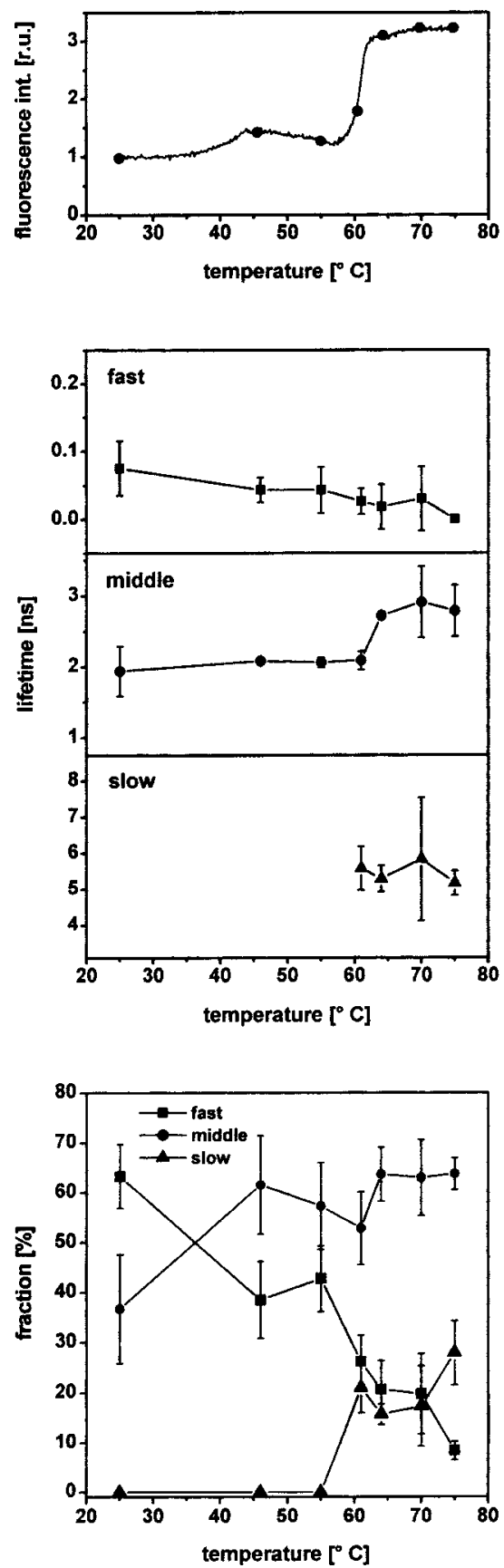

green
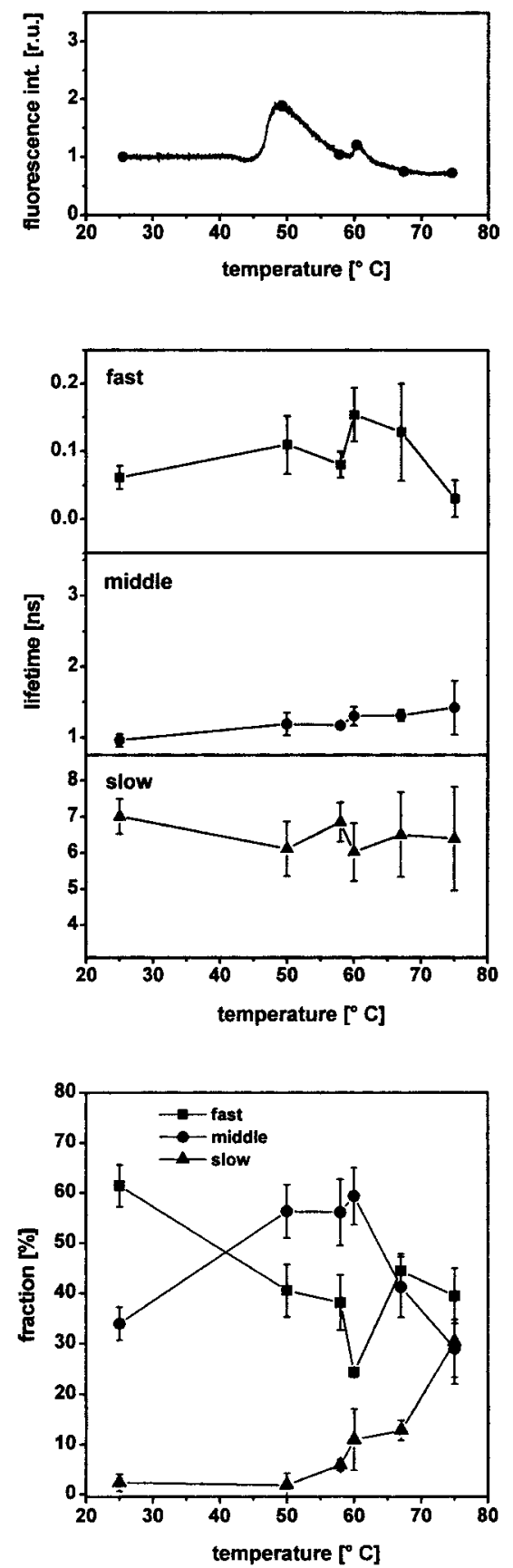

Figure 2. Chlorophyll fluorescence decay parameters-lifetimes and fractional contributions to steady-state fluorescence intensity (fractions) — of 3 h greening and green barley leaves linearly preheated to selected temperatures corresponding to important points in their FTC (curves above). The FTC were adopted from Fig. 1. Fluorescence decay data were fitted by a two- or three-exponential decay model according to $\chi^{2}$ values and residuals. Errors represent $\pm \mathrm{SD}$ calculated from decay parameters, which were evaluated from 4-7 repetitions.

Introduction). Heating of these leaves to $60^{\circ} \mathrm{C}$ and above induced a release of free Chl $a$ molecules from PPC, as the additional decay component with a lifetime of about $6 \mathrm{~ns}\left(\tau_{\text {slow }}\right)$ was distinguished. However, the fraction of this slow component was too low to explain the fluorescence rise to the M2 FTC region. A middle component with $\tau_{\text {middle }}$ of about $2.8 \mathrm{~ns}$ is mainly responsible for the fluorescence rise to the $\mathrm{M} 2$ region because its fraction is about $65 \%$ for leaves preheated to temperatures above $60^{\circ} \mathrm{C}$ (Fig. 2).
Analysis of fluorescence decays of preheated green leaves showed similar results (Fig. 2, right panels). In this case the slow component with $\tau_{\text {slow }}$ around $6 \mathrm{~ns}$ was also distinguished in unheated leaves; however, its contribution to the steady-state fluorescence level was below $5 \%$ for samples preheated up to $50^{\circ} \mathrm{C}$. Preheating of green leaves to $61^{\circ} \mathrm{C}$, when the $\mathrm{M} 2$ maximum in its FTC appeared, did not lead to a significant increase of the fraction with this long lifetime. Again, a middle component with 


\section{$1.5 \mathrm{~h}$ greening}
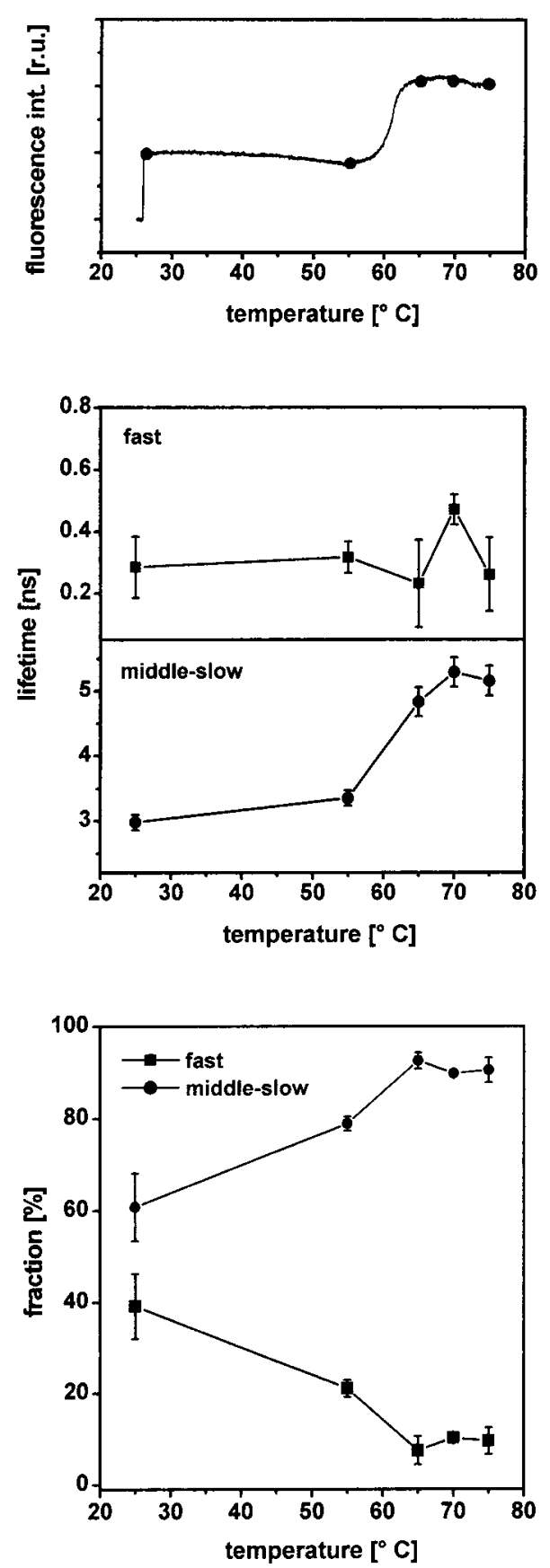

Figure 3. Chlorophyll fluorescence decay parameters-lifetimes and fractions - of $1.5 \mathrm{~h}$ greening barley leaves linearly preheated to selected temperatures corresponding to important points in the FTC (curves in the upper panel, adopted from Fig. 1). Fluorescence decay data were successfully fitted by a two-exponential decay model. Errors represent \pm SD calculated from decay parameters, which were evaluated from 4-6 repetitions.

$\tau_{\text {middle }}$ of about $1 \mathrm{~ns}$ dominates in the steady-state chlorophyll fluorescence of green leaf preheated to the temperature of the M2 FTC maximum. For higher preheating temperatures the contribution of the middle $1 \mathrm{~ns}$ component decreases at the expense of the slow component (Fig. 2).

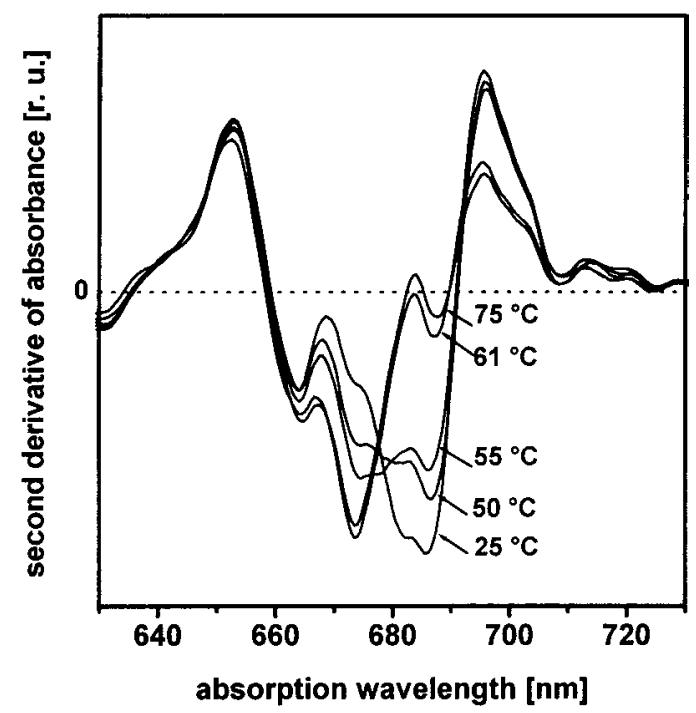

Figure 4. Second derivatives of absorption spectra in the red spectral region of $1.5 \mathrm{~h}$ greening leaves linearly preheated to selected temperatures.

The finding that the fluorescence rise to the M2 FTC region originates from the fluorescence decay component with the middle fluorescence lifetime, which, moreover, differs in the lifetime value for green and $3 \mathrm{~h}$ greening leaves, led us to measure in addition the fluorescence decays for preheated $1.5 \mathrm{~h}$ greening barley leaves having an extremely low chlorophyll content (Table 1). In this case the fluorescence data were successfully fitted by two decay components for all preheating temperatures (Fig. 3). The fast component with $\tau_{\text {fast }}$ of about $0.2-0.4$ ns was slightly higher, and its contribution to the steady-state fluorescence was lower than that in previous unheated samples. A dominant middle component with $\tau_{\text {middle }}$ of about $3 \mathrm{~ns}$ changed to the slow component with about $5 \mathrm{~ns}$ lifetime after preheating of leaves to above $55^{\circ} \mathrm{C}$. The fraction of this slow component was around $90 \%$ after preheating to these temperatures. It is possible that this slow component consists of two components with similar fluorescence lifetimes, including the $6 \mathrm{~ns}$ component distinguished in previous experiments. Anyway, this result can be accounted as evidence that for $1.5 \mathrm{~h}$ greening leaves the irreversible fluorescence rise to the M2 FTC region reflects the release of free Chl $a$ molecules from denatured PPC. Chl $a$ molecules are probably released to the surrounding thylakoid lipid phase because in water they form practically nonfluorescing aggregates (48). The fact that $\mathrm{Chl} a$-containing PPC denature at the temperature range of the fluorescence rise also was supported by the measurements of pronounced changes in their absorption spectra. Figure 4 clearly shows, using the second derivatives of the absorption spectra of the $1.5 \mathrm{~h}$ greening leaf in the red region, that the main red absorption maximum is shifted to shorter wavelengths by about $7 \mathrm{~nm}$ (to $672-673 \mathrm{~nm}$ ) during heating in the temperature range of the fluorescence rise.

However, how can an explanation be found for why the chlorophyll fluorescence of samples with higher chlorophyll content ( $3 \mathrm{~h}$ greening and green leaves), after heating to temperatures of the M2 FTC region, comes from decay components with fluorescence lifetimes shorter than those of $1.5 \mathrm{~h}$ greening leaves? It even seems that the higher the Chl $a$ content in barley leaves, the shorter the fluorescence lifetime of the decay component (see Table 1, Fig. 2). The simplest explanation of this phenomenon is that the Chl 


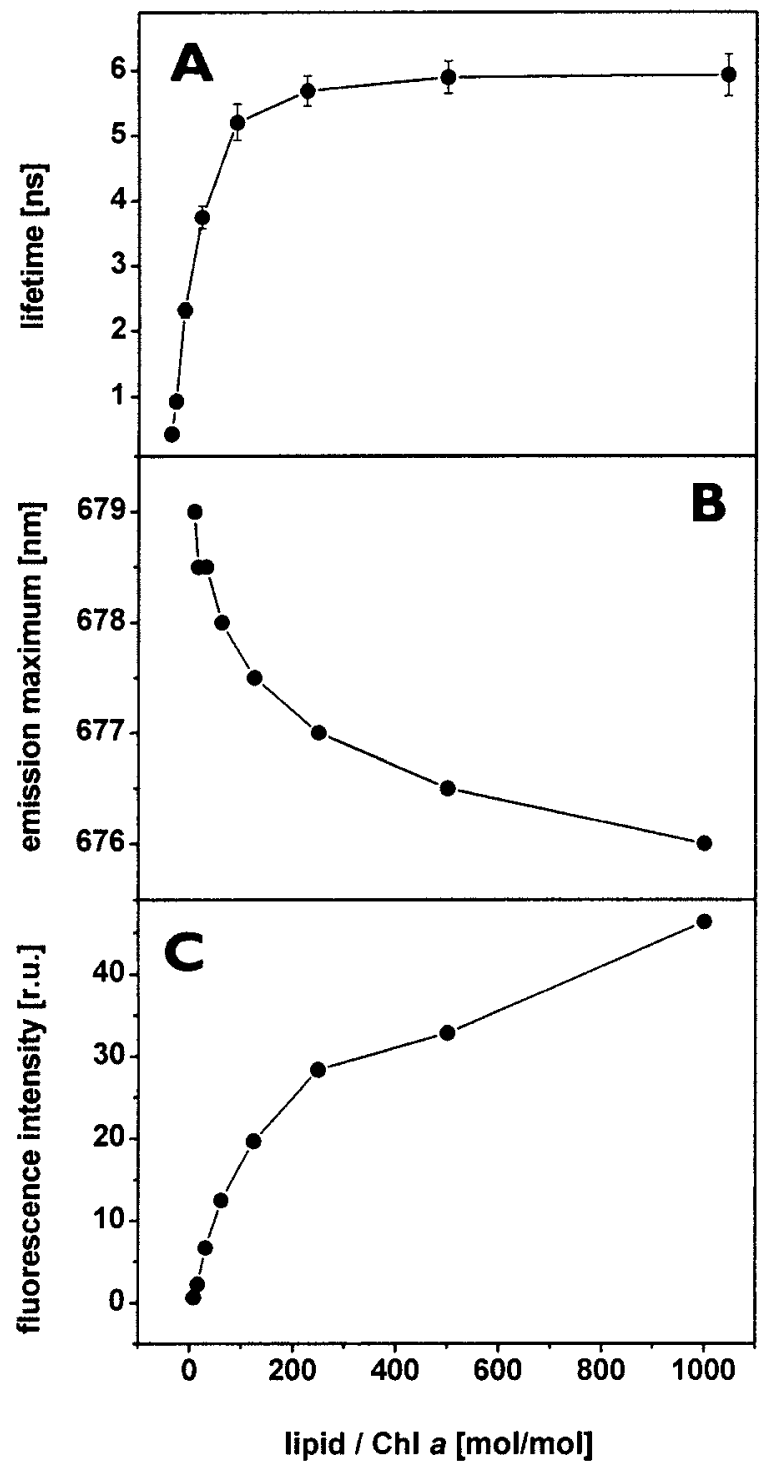

Figure 5. Chlorophyll fluorescence parameters of liposomes with different lipid/Chl $a$ ratios. Fluorescence lifetimes (panel A) were evaluated by a oneexponential decay model. For liposomes with low lipid/Chl $a$ ratios of 8 and 16, small decay components $(\sim 10 \%$ fraction) with fluorescence lifetimes of 2.5 and $3 \mathrm{~ns}$, respectively, also were distinguished. For these two samples, only the fluorescence lifetimes of the main decay component are displayed. Errors represent a confidence interval for the $67 \%$ level of confidence evaluated by the fitting procedure. Panel B shows the position of the steady-state emission maximum and panel $\mathrm{C}$ the height of the emission maximum related to the $\mathrm{Chl} a$ concentration in the sample (for details see the Materials and Methods).

$a$ molecules, released from PPC at the temperature of the fluorescence rise, aggregate in particular in leaves with a higher Chl $a$ content. The shorter fluorescence lifetime of the aggregates could correspond with the lower fluorescence yield demonstrated by the lower M2 FTC region (see Fig. 1).

\section{Liposomes with different lipid-Chl $a$ ratios-a model experiment}

To support the idea that free $\mathrm{Chl} a$ molecules in the lipid phase of thylakoids tend to aggregate at high $\mathrm{Chl} a$ concentrations, we

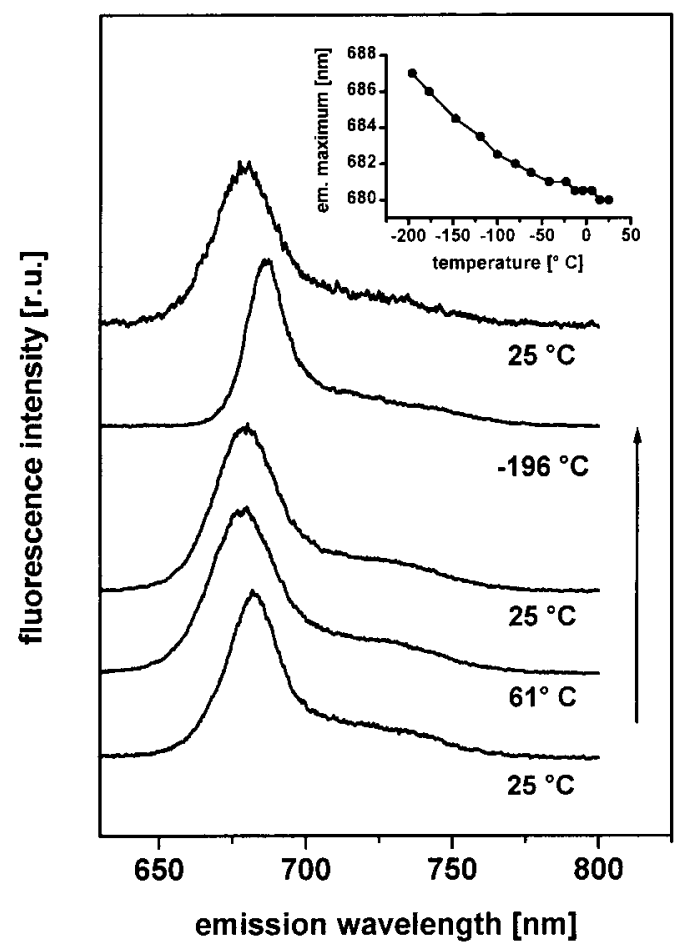

Figure 6. Fluorescence emission spectra of IML barley leaf normalized at different temperatures (normalized for fluorescence intensity maximum). The room temperature-adapted leaf (the spectrum below) was linearly heated to $61^{\circ} \mathrm{C}$ (second spectrum, see the arrow), then cooled to room temperature (third spectrum), then frozen in liquid nitrogen (fourth spectrum) and then heated to room temperature (fifth spectrum). The spectra are vertically shifted. Insert: The change of position of the emission maximum during heating of the IML leaf from $-196^{\circ} \mathrm{C}$ to room temperature (i.e. from the fourth spectrum to the fifth spectrum).

measured steady-state fluorescence emission spectra and fluorescence lifetimes of liposomes with different lipid/Chl $a$ ratios. Apart from Chl $a$ the liposomes consisted of MGDG, DGDG, PG and SQDG (with a molar ratio of 50:25:12.5:12.5), mimicking the natural lipid composition of thylakoid membranes (see Murata and Siegenthaler [49]). The Chl $a$ concentration was kept the same for samples with liposomes having lipid/Chl $a$ molar ratios from 8 to 125; however, for practical reasons, in the samples with liposomes of higher lipid/Chl $a$ ratios, lipid concentration was constant, and Chl $a$ content changed. Figure 5 shows fluorescence lifetimes, positions of room temperature emission maxima and fluorescence intensities in the emission maxima (normalized to $\mathrm{Chl} a$ content in the sample) for liposomes with different lipid/Chl $a$ ratios.

The data of fluorescence decay measurements were successfully fitted by the one-exponential decay model (Fig. 5a), but for liposomes with lipid/Chl $a$ ratios of 8 and 16, slight $(\sim 10 \%$ fraction) additional decay components with 2.5 and 3 ns lifetimes, respectively, were distinguished (not shown). For these two samples, only the fluorescence lifetimes of the main decay component are displayed. The results demonstrate that increase of Chl $a$ concentration in this lipid phase leads to formation of some Chl $a$ aggregates, the fluorescence lifetime of which rapidly decreases with decreasing lipid/Chl $a$ ratios. This conclusion is supported by measurements of steady-state fluorescence emission spectra of the liposomes at room temperature. Increasing Chl $a$ content in liposomes led to a shift of the emission maximum to 
higher wavelengths (Fig. 5b) and to a pronounced decrease of Chl $a$ fluorescence yield, as can be deduced from the decreasing relative fluorescence intensity related to the $\mathrm{Chl} a$ content in the sample (Fig. 5c).

The dependencies shown in Fig. 5 can be explained simply using the findings published in earlier articles. It has been shown that increased concentration of pigments in model systems leads to fluorescence quenching and a decrease of fluorescence lifetime. The effects are usually explained as a consequence of excitation energy transfer, when the mean distance between pigments decreases below the critical one, and the longer-wavelength emission of aggregates starts to dominate (50-53). Agrawal et al. (53), for example, have shown a concentration-dependent decrease in both quantum yield and fluorescence lifetime for Chl $a$ in lecithin monolayers.

These results show that heat-induced release of a low amount of free Chl $a$ from PPC to thylakoid lipids can increase total Chl $a$ fluorescence yield, whereas release of a high amount of free $\mathrm{Chl}$ $a$ to the lipids leads to an opposite effect.

\section{DISCUSSION}

\section{Origin of fluorescence rise at $55-60^{\circ} \mathrm{C}$}

It has been reported several times that the high-temperature fluorescence rise to the M2 FTC region, appearing around 55$60^{\circ} \mathrm{C}$, is pronounced for samples with higher $\mathrm{Chl} a / \mathrm{Chl} b$ ratios (5,28,30-32), indicating a reduced content of LHCII (54). The highest fluorescence rise was detected for bundle sheath chloroplasts (28) and for leaves at early stages of greening (Fig. 1) $(5,31,32)$, both lacking grana thylakoids. Thus chlorophyll in the stromal thylakoids seems to be responsible for this fluorescence rise, as proposed by Downton and Berry (28). Our measurements of fluorescence lifetimes with $1.5 \mathrm{~h}$ greening barley leaves lacking grana stacks $(31,42)$ showed that the fluorescence rise to the M2 FTC region in these leaves (Fig. 1) originates from the fluorescence decay component with about 5 ns lifetime (Fig. 3). This component can be attributed to Chl $a$ released from PPC because its lifetime is very close to the lifetime range of free $\mathrm{Chl} a$ in solution ( $\sim 5.5-6.5$ ns) (55). Moreover, this $5 \mathrm{~ns}$ component noticeably resembles the decay component of the monomeric Chl $a$ form in membrane lipids (56). This attribution is further supported by the findings that 1) the Chl $a$ fluorescence maximum of this leaf in the M2 FTC region (i.e. above $60^{\circ} \mathrm{C}$ ) was at $675 \mathrm{~nm}(5)$, which is shorter than the maxima of known native PPC and corresponds to a greater extent to the emission maximum of $\mathrm{Chl} a$ in liposomes with higher lipid/ Chl $a$ ratios (see Fig. 5b) (e.g. 57); 2) the fluorescence rise to the M2 FTC region follows a dramatic shift in the main red absorption maximum to shorter wavelengths, implying denaturations of $\mathrm{Chl}$ $a$-containing protein complexes within the leaf (Fig. 6); and 3) $\mathrm{Chl}$ $a$ in leaves is stable at least up to $75^{\circ} \mathrm{C}(5)$. In this $1.5 \mathrm{~h}$ greening leaf the fluorescence rise to the M2 FTC region can reflect a release of Chl $a$ from PSI and PSII cores because only these chlorophyllcontaining complexes are in the thylakoid membranes of its chloroplasts (42).

The fluorescence level in the M2 FTC region of leaves with a higher Chl $a$ content mainly constitutes the fluorescence decay components with shorter fluorescence lifetimes. They were around $2.8 \mathrm{~ns}$ for $3 \mathrm{~h}$ greening barley leaves, with a Chl $a$ area concentration of about $2 \mu \mathrm{g} \mathrm{cm}^{-2}$, and even around $1 \mathrm{~ns}$ for green leaves, with an area concentration of about $22 \mu \mathrm{g} \mathrm{cm}^{-2}$ (see Fig. 2, Table 1). On the basis of the measurements of fluorescence lifetimes and steady-state emission spectra of liposomes with different lipid/ Chl $a$ ratios (Fig. 5), we suggest that this shortening of the lifetime reflects the formation of aggregates of the released Chl $a$ in the surrounding lipid phase.

The experiments in the model systems showed that $\mathrm{Chl}$ $a$ aggregation in liposomes is a consequence of the low lipid/Chl $a$ ratio. Interestingly, even a monotonous decrease in the fluorescence lifetime with the decreasing lipid/Chl $a$ ratio in liposomes was found. The $\mathrm{Chl} a$ aggregation was accompanied by a shift in the emission maximum to higher wavelengths and by a decrease in Chl $a$ fluorescence quantum yield (Fig. 5). Both these phenomena were observed in our leaf types preheated to the temperature of the M2 FTC region. Whereas for the $1.5 \mathrm{~h}$ greening leaf the emission maximum in the M2 FTC region was at $675 \mathrm{~nm}$, for barley leaves with higher $\mathrm{Chl} a$ contents (green, chlorina $\mathrm{f} 2$, IML) the maximum appeared at $679-680 \mathrm{~nm}(5)$. There is nearly a numerical agreement of these results with the results obtained with liposomes of very high lipid/Chl $a$ ratio and very low lipid/ $\mathrm{Chl} a$ ratio, respectively (Fig. 5b). The fact that the higher the $\mathrm{Chl}$ $a$ content in the leaves the higher is the suppression of the M2 FTC region (Fig. 1, Table 1) is also in accordance with the concept of aggregation of released $\mathrm{Chl} a$.

Another similarity between the $\mathrm{Chl} a$-containing liposomes and the Chl $a$ forms appearing in the M2 FTC region is in their absorption characteristics. The main red absorption band of the liposomes of all used lipid/Chl $a$ ratios had a maximum at $671 \mathrm{~nm}$ (results not shown), which is produced by the Chl $a$-lipid interaction (58). All the barley leaf types mentioned in this work preheated to temperatures of M2 FTC region show very similar main red absorption maxima at 671-673 nm (Fig. 4) (5).

Recently, it has been reported that the fluorescence rise to the M2 FTC region in IML barley leaves corresponds with the appearance of the main $77 \mathrm{~K} \mathrm{Chl} a$ emission band with a maximum around $688 \mathrm{~nm}$ (32). To clarify how this $77 \mathrm{~K}$ emission band corresponds with the $679-680 \mathrm{~nm} \mathrm{Chl} a$ emission appearing in the M2 FTC region of the IML leaf (5), we also measured the temperature dependence of fluorescence emission spectra of IML leaves after preheating to $61^{\circ} \mathrm{C}$ (the temperature of the M2 FTC maximum, see Fig. 1). The room temperature-adapted IML leaf (Fig. 6, spectrum below) was linearly heated to $61^{\circ} \mathrm{C}$ (second spectrum, along the arrow), then cooled again to room temperature (third spectrum), then frozen in liquid nitrogen (fourth spectrum) and then heated back to room temperature (fifth spectrum). It is clearly seen that 1) the spectral blueshift occurring during the rise to the M2 FTC region (5) is irreversible, as can be expected from the irreversibility of the fluorescence rise (Fig. 1) (34); 2) freezing of the leaf preheated to $61^{\circ} \mathrm{C}$ in liquid nitrogen induced an appearance of the emission maximum strongly redshifted by about $7 \mathrm{~nm}$; and 3) this shift is fully reversible. A detailed temperature dependence of the emission maximum from $-196^{\circ} \mathrm{C}$ to $+25^{\circ} \mathrm{C}$ shows that the spectral change is monotonous (Fig. 6, insert), suggesting that the Chl $a$ emission forms detected in the M2 FTC region and at $77 \mathrm{~K}$ are the same and do not reflect the emission of native PPC.

The fluorescence rise to the M2 FTC region is probably connected with the heat-induced enhancement of the Chl $a$ chemiluminescence observed in bean chloroplasts around $60^{\circ} \mathrm{C}$ (59), which was attributed to emission of free Chl $a$ excited by oxygen-dependent lipid peroxidation. Very similar oxygendependent $\mathrm{Chl} a$ chemiluminescence was detected with linearly heated barley leaves $(60)$. 


\section{Origin of fluorescence decrease in FTC above the M2 maximum}

The concept of the aggregation of released Chl $a$ from PPC into the surrounding thylakoid lipids also can be used for interpretation of a gradual fluorescence decrease, which appears within the M2 FTC region of samples with high chlorophyll content (Fig. 1). It is important to note that this gradual decrease is irreversible (27), as also the fluorescence rise to the M2 region (see Fig. 1). The most pronounced relative fluorescence decrease in the M2 region was observed with green barley leaf in the temperature range of 61$67^{\circ} \mathrm{C}$ (Figs. 1 and 2). The fluorescence decay measurements with preheated green leaves (Fig. 4, right panels) showed that at the M2 FTC maximum $\left(61^{\circ} \mathrm{C}\right)$ the fluorescence originates mainly from the middle decay component with a fluorescence lifetime of about $1 \mathrm{~ns}$. This lifetime did not change with an increase in the preheating temperature to $67^{\circ} \mathrm{C}$; however, its relative fraction decreased greatly in favor of the fast component with a lifetime below 0.2 ns. Interestingly, the third decay component with the fluorescence lifetime of 6-7 ns, which is attributed to free $\mathrm{Chl} a$, contributed to the steady-state fluorescence by about $10 \%$ only for preheating temperatures of $61-67^{\circ} \mathrm{C}$. Similar temperature-dependent changes of the fluorescence lifetimes and fractions also were detected in this temperature range for preheated chlorina $f 2$ leaves (data not shown), at which the significant fluorescence decrease in the M2 FTC region also appeared (Fig. 1). We suggest that fluorescence decrease in the M2 FTC region reflects gradual forming of the Chl $a$ aggregates, which were detected in liposomes with a lipid/Chl $a$ ratio of 16 or lower. These aggregates in liposomes have extremely low fluorescence yield, and the lifetime of their main decay component was below $1 \mathrm{~ns}$ (Fig. 5a). It is also probable that the fast fluorescence decay component, which was detected in green (and chlorina f2) leaves after preheating to $67^{\circ} \mathrm{C}$ is related to the fast component, which was also observed in model liposomes with such a low lipid/Chl $a$ ratio. The fluorescence level at the M2 FTC region also can be influenced by the presence of xanthophylls, which modify the interaction of chlorophylls with the surrounding molecules in the lipids phase (57).

Acknowledgements—We thank Pavel Tomek, Pavla Kamínková and Dr. Pavel Krchňák for technical assistance. We also thank Prof. D. Simpson for providing us with seeds of chlorina $f 2$ barley and K. Klem for their reproduction. This work was supported by the Ministry of Education of the Czech Republic (grant MSM 153100010) and the Committee for Scientific Research (KBN) of Poland (grant 6 P04A 028 19).

\section{REFERENCES}

1. Schreiber, U. and J. A. Berry (1977) Heat induced changes of chlorophyll fluorescence in intact leaves correlated with damage of the photosynthetic apparatus. Planta 136, 233-238.

2. Schreiber, U. and P. A. Armond (1978) Heat-induced changes of chlorophyll fluorescence in isolated chloroplasts and related heat damage at the pigment level. Biochim. Biophys. Acta 502, 138-151.

3. Havaux, M. (1992) Stress tolerance of photosystem II in vivo. Antagonistic effects of water, heat, and photoinhibition stresses. Plant Physiol. 100, 424-432.

4. Kuropatwa, R., J. Nauš, M. Mašláň and L. Dvořák (1992) Basic properties of the chlorophyll fluorescence temperature curve in barley leaves. Photosynthetica 27, 129-138.

5. Ilík, P., R. Kouřil, J. Fiala, J. Nauš and F. Vácha (2000) Spectral characterization of chlorophyll fluorescence in barley leaves during linear heating. Analysis of high-temperature fluorescence rise around $60^{\circ}$ C. J. Photochem. Photobiol. B: Biol. 59, 103-114.

6. Ducruet, J. M. and Y. Lemoine (1985) Increased heat sensitivity of the photosynthetic apparatus in triazine-resistant biotypes from different plant species. Plant Cell Physiol. 26, 419-429.

7. Bukhov, N. G., S. C. Sabat and P. Mohanty (1990) Analysis of chlorophyll $a$ fluorescence changes in weak light in heat-treated Amaranthus chloroplasts. Photosynth. Res. 23, 81-87.

8. Nauš, J., R. Kuropatwa, T. Klinkovský, P. Ilík, J. Lattová and Z. Pavlová (1992) Heat injury of barley leaves detected by the chlorophyll fluorescence temperature curve. Biochim. Biophys. Acta 1101, 359362.

9. Pospísili, P. and E. Tyystjärvi (1999) Molecular mechanism of hightemperature-induced inhibition of acceptor side of photosystem II. Photosynth. Res. 62, 55-66.

10. Briantais, J. M., J. Dacosta, Y. Goulas, J. M. Ducruet and I. Moya (1996) Heat stress induces in leaves an increase of the minimum level of chlorophyll fluorescence, $\mathrm{F}_{0}$ : a time-resolved analysis. Photosynth. Res. 48, 189-196.

11. Yamane, Y., T. Shikanai, Y. Kashino, H. Koike and K. Satoh (2000) Reduction of $\mathrm{Q}_{\mathrm{A}}$ in the dark: another cause of fluorescence $\mathrm{F}_{0}$ increases by high temperatures in higher plants. Photosynth. Res. 63, 23-34.

12. Bukhov, N. G. and R. Carpentier (2000) Heterogeneity of photosystem II reaction centers as influenced by heat treatment of barley leaves. Physiol. Plant. 110, 279-285.

13. Kouřil, R., P. Ilík, P. Tomek, J. Nauš and A. Poulíčková (2001) Chlorophyll fluorescence temperature curve on Klebsormidium flaccidum cultivated at different temperature regimes. J. Plant Physiol. 158 , 1131-1136.

14. Havaux, M., M. Ernez and R. Lannoye (1988) Correlation between heat tolerance and drought tolerance in cereals demonstrated by rapid chlorophyll fluorescence tests. J. Plant Physiol. 133, 555-560.

15. Lazár, D. and P. Ilík (1997) High-temperature induced chlorophyll fluorescence changes in barley leaves. Comparison of the critical temperatures determined from fluorescence induction and from fluorescence temperature curve. Plant Sci. 124, 159-164.

16. Pospíšil, P. and J. Nauš (1998) Theoretical simulation of temperature induced increase of quantum yield of minimum chlorophyll fluorescence $\Phi_{\mathrm{F} 0} . J$. Theor. Biol. 93, 125-130.

17. Pospíšil, P., J. Skotnica and J. Nauš (1998) Low and high temperature dependence of minimum $\mathrm{F}_{0}$ and maximum $\mathrm{F}_{\mathrm{M}}$ chlorophyll fluorescence in vivo. Biochim. Biophys. Acta 1363, 95-99.

18. Klimov, V. V. and A. A. Krasnovskii (1981) Pheophytin as the primary electron acceptor in photosystem 2 reaction centres. Photosynthetica 15, 592-609.

19. Yamane, Y., Y. Kashino, H. Koike and K. Satoh (1997) Increases in the fluorescence $F_{0}$ level and reversible inhibition of photosystem II reaction center by high-temperature treatments in higher plants. Photosynth. Res. 52, 57-64.

20. Allakhverdiev, S. I., Y. M. Feyziev, A. Ahmed, H. Hayashi, J. A. Aliev, V. V. Klimov, N. Murata and R. Carpentier (1996) Stabilization of oxygen evolution and primary electron transport reactions in photosystem II against heat stress with glycinebetaine and sucrose. J. Photochem. Photobiol. B: Biol. 34, 149-157.

21. Krause, G. H. and E. Weis (1991) Chlorophyll fluorescence and photosynthesis. The basics. Annu. Rev. Plant Physiol. 42, 313-349.

22. Govindjee (1995) 63 years since Kautsky — chlorophyll $a$ fluorescence. Aust. J. Plant Physiol. 22, 131-160.

23. Williams, W. P. and K. Gounaris (1992) Stabilization of PS-II-mediated electron transport in oxygen-evolving PS-II core preparations by the addition of compatible co-solutes. Biochim. Biophys. Acta 1100, 92-97.

24. Armond, P. A., O. Björkman and L. A. Staehelin (1980) Dissociation of supramolecular complexes in chloroplast membranes-a manifestation of heat damage to the photosynthetic apparatus. Biochim. Biophys. Acta 601, 433-442.

25. Sundby, C. and B. Andersson (1985) Temperature-induced reversible migration along the thylakoid membrane of photosystem II regulates its association with LHC-II. FEBS Lett. 191, 24-28.

26. Sundby, C., A. Melis, P. Mäenpää and B. Andersson (1986) Temperature-dependent changes in antenna size of photosystem II. Reversible conversion of photosystem II $\alpha$ to photosystem II $\beta$. Biochim. Biophys. Acta 851, 475-483.

27. Nauš, J., M. Šnáblová, L. Dvořák and Z. Kupka (1986) Temperature 
dependence of in vivo chlorophyll a fluorescence. Acta UPO, Fac. Rer. Nat. 85 (Physica XXV), 47-61.

28. Downton, W. J. S. and J. A. Berry (1982) Chlorophyll fluorescence at high temperature. Biochim. Biophys. Acta 679, 474-478.

29. Gaevsky, N. A., V. G. Ladygin and V. M. Gold (1989) New data on the nature of the high-temperature rise of chlorophyll fluorescence. Fiziol. Rast. 36, 274-277. [In Russian]

30. Špunda, V., J. Kalina, J. Nauš, R. Kuropatwa, M. Mašláň and M. Marek (1993) Responses of photosystem 2 photochemistry and pigment composition in needles of Norway spruce saplings to increased radiation level. Photosynthetica 28, 401-413.

31. Ilík, P., J. Nauš, D. Cikánek and R. Novotný (1995) Chlorophyll fluorescence changes at high temperatures induced by linear heating of greening barley leaves. Photosynth. Res. 44, 271-275.

32. Ilík, P., J. Nauš, V. Špunda, V., M. Čajánek, D. Cikánek and P. Pospíšil (1997) High temperature chlorophyll fluorescence rise within $61-67^{\circ} \mathrm{C}$. Spectroscopic study with intermittent light grown barley leaves. $J$. Photochem. Photobiol. B: Biol. 39, 243-249.

33. Ilík, P., M. Vystrčilová, J. Nauš and J. Kalina (1997) Chlorophyll fluorescence temperature curves of spruce needles from different whorls of the tree. Photosynthetica 34, 477-480.

34. Kuznetsova, E. A. (1981) Study of temperature dependence of plant leaf fluorescence. Dokl. Akad. Nauk USSR 256, 893-894. [In Russian]

35. Nauš, J., L. Dvořák, R. Kuropatwa and M. Mašláň (1992) Transitions in the thylakoid membranes of barley leaves studied by chlorophyll fluorescence temperature curve. Photosynthetica 27, 563-570.

36. Ilík, P., J. Nauš, D. Cikánek, V. Špunda, M. Čajánek, R. Novotný and D. Žák (1995) An investigation of high-temperature region of chlorophyll fluorescence temperature curve. In Photosynthesis: from Light to Biosphere, Vol. IV (Edited by P. Mathis), pp. 885-888. Kluwer Academic Publishers, Dordrecht, The Netherlands.

37. McCain, D. C., J. Croxdale and J. L. Markley (1989) Thermal damage to chloroplast envelope membranes. Plant Physiol. 90, 606-609.

38. Santarius, K. A., M. Exner and R. Thebudlassak (1991) Effects of high temperature on the photosynthetic apparatus in isolated mesophyll protoplasts of Valerianella locusta L. Betcke. Photosynthetica 25, $17-26$

39. Lichtenthaler, H. K. (1987) Chlorophylls and carotenoids: pigments of photosynthetic biomembranes. Methods Enzymol. 48, 350-382.

40. Myśliwa-Kurdziel, B., X. Barthelémy, K. Strzałka and F. Franck (1997) The early stages of photosystem II assembly monitored by measurements of fluorescence lifetime, fluorescence induction and isoelectric focusing of chlorophyll-proteins in barley etiochloroplasts. Plant Cell Physiol. 38, 1187-1196.

41. Myśliwa-Kurdziel, B., F. Franck and K. Strzałka (1999) Analysis of fluorescence lifetime of protochlorophyllide and chlorophyllide in isolated etioplast membranes measured from multifrequency cross-correlation phase fluorometry. Photochem. Photobiol. 70, 616-623.

42. Ohashi, K., A. Murakami, A. Tanaka, H. Tsuji and F. Yoshihiko (1992) Developmental changes in amount of thylakoid components in plastids of barley leaves. Plant Cell Physiol. 33, 371-377.

43. Dreyfuss, B. W. and J. P. Thornber (1994) Assembly of the lightharvesting complexes (LHCs) of photosystem II. Plant Physiol. 106, 829-839.

44. Król, M., M. D. Spangfort, N. P. A. Huner, G. Öquist, P. Gustafsson and S. Jansson (1995) Chlorophyll $a / b$-binding proteins, pigment conversions, and early light-induced proteins in chlorophyll $b$-less barley mutant. Plant Physiol. 107, 873-883.

45. Havaux, M. and F. Tardy (1997) Thermostability and photostability of photosystem II in leaves of the chlorina-f2 barley mutant deficient in light-harvesting chlorophyll $a / b$ protein complexes. Plant Physiol. 113, 913-923.

46. Mannan, M. R., S. Perizanan, G. Kulansaivelu and S. Bose (1986) Species specific chlorophyll $a$ fluorescence-temperature profile at high temperatures in the leaves. Photosynth. Res. 8, 87-92.

47. Govidjee, M. Van de Ven, J. Cao, C. Royer and E. Gratton (1993) Multifrequency cross-correlation phase fluorometry of chlorophyll $a$ fluorescence in thylakoid and PSII-enriched membranes. Photochem. Photobiol. 58, 438-445.

48. Journeaux, R., A. Hochapfel and R. Viovy (1969) Existence et nature des formes agrégées de la chlorophylle $a$ dans les solvants binaires. II-Étude des spectres de fluorescence. J. Chim. Phys. 66, 1474-1478.

49. Murata, N. and P. A. Siegenthaler (1997) Lipids in photosyntesis. An overview. In Lipids in Photosyntesis. Structure, Function and Genetics (Edited by P. A. Siegenthaler and N. Murata), pp. 1-20. Kluwer Academic Publishers, Dordrecht, The Netherlands.

50. Tweet, A. G., W. D. Bellamy and G. L. Gaines Jr. (1964) Fluorescence quenching and energy transfer in monomolecular films containing chlorophyll. J. Chem. Phys. 41, 2068-2077.

51. Knox, R. S. (1973) Transfer of electronic excitation energy in condensed systems. In Primary Molecular Events in Photobiology (Edited by A. Checcucci and R. A. Weale), pp. 45-77. Elsevier, Amsterdam.

52. Trosper, T., R. B. Park and K. Sauer (1968) Excitation transfer by chlorophyll $a$ in monolayers and the interaction with chloroplast glycolipides. Photochem. Photobiol. 7, 451-469.

53. Agrawal, M. L., J. P. Chauvet and L. K. Patterson (1985) Effect of molecular organization on photophysical behavior: lifetime and steadystate fluorescence of chlorophyll $a$ singlets in monolayers of dioleoylphosphatidylcholine at the nitrogen-water interface. J. Phys. Chem. 89, 2979-2982.

54. Anderson, J. M., W. S. Chow and D. J. Goodchild (1988) Thylakoid membrane organization in sun/shade acclimation. Aust. J. Plant Physiol. 15, 11-26.

55. Connoly, J. S., A. F. Janzen and E. B. Samuel (1982) Fluorescence lifetimes of chlorophyll $a$ : solvent, concentration and oxygen dependence. Photochem. Photobiol. 36, 559-563.

56. Picard, G., J. Aghion, C. Le Crom and R. M. Leblanc (1989) Fluorescence properties of Langmuir-Blodgett films of chlorophyll $a$ mixed with membrane lipids. Thin Solid Films 180, 31-42.

57. Gruszecki, W. I., M. Matula, B. Myśliwa-Kurdziel, P. Kernen, Z. Krupa and K. Strzałka (1997) Effect of xantophyll pigments on fluorescence of chlorophyll $a$ in LHC II embedded to liposomes. J. Photochem. Photobiol. B: Biol. 37, 84-90.

58. Murata, N. and N. Sato (1978) Studies of the absorption spectra of chlorophyll $a$ in aqueous dispersions of lipids from the photosynthetic membranes. Plant Cell Physiol. 19, 401-410.

59. Hideg, E. and I. Vass (1993) The $75^{\circ} \mathrm{C}$ thermoluminescence band of green tissues-chemiluminescence from membrane-chlorophyll interaction. Photochem. Photobiol. 58, 280-283.

60. Skotnica, J., J. Fiala, P. Ilík and L. Dvořák (1999) Thermally induced chemiluminescence of barley leaves. Photochem. Photobiol. 69, 211-217. 